Original Research Paper

\title{
Comparative Effects and Phytotoxicity of Photo Fenton Solutions and Acid Rains on Cucumber (Cucumis Sativus) Plants: Treats and Console
}

\author{
${ }^{1}$ Fawzy Eissa, ${ }^{2}$ Sayuri Bandai, ${ }^{3}$ Nour El-Hoda Zidan, ${ }^{2,4}$ Ilemobayo Oguntimehin and ${ }^{2}$ Hiroshi Sakugawa \\ ${ }^{1}$ Department of Environment and Bio-Agriculture, Faculty of Agriculture, Al-Azhar University, Nasr City, Cairo, Egypt \\ ${ }^{2}$ Department of Environmental Dynamics and Management, Graduate School of Biosphere Science, \\ Hiroshima University, 1-7-1 Kagamiyama, Higashi, Hiroshima 739-8521, Japan \\ ${ }^{3}$ Department of Pesticides Chemistry and Toxicology, Faculty of Agriculture, Kafrelsheikh University, Kafr El-Sheikh, Egypt \\ ${ }^{4}$ Department of Chemical Sciences, Ondo State University of Science and Technology, Ondo State, Nigeria
}

\author{
Article history \\ Received: $15-02-2020$ \\ Revised: 15-04-2020 \\ Accepted: $19-05-2020$ \\ Corresponding Author: \\ Fawzy Eissa \\ Department of Environment \\ and Bio-Agriculture, Faculty of \\ Agriculture, Al-Azhar \\ University, Cairo, Egypt \\ Email: fawzy.eissa@yahoo.com
}

\begin{abstract}
The Eco-physiological assessments of variable parameters known to be essential for proper plant growth and health were determined in cucumber plants exposed to short term treatments in 42 days using two broad classification types; Photo Fenton solution generating $\mathrm{OH}$ radicals and simulated acids. Solutions containing different classification of scavengers of $\mathrm{OH}$ radicals and mannitol were employed as Controls. Results indicated that the acid rain and photo Fenton solution both decreased the photosynthetic rate $\left(\mathrm{A}_{\max }\right)$, stomatal conductance $\left(\mathrm{g}_{\mathrm{s}}\right)$, photochemical efficiency of PSII in the dark $\left(\mathrm{F}_{\mathrm{v}} / \mathrm{F}_{\mathrm{m}}\right)$, SPAD chlorophyll and they imparted severe foliar injuries on cucumber leaves. The acids treatments have the highest negative impact followed by the photo Fenton Solution. The mechanisms of phytotoxicity of the two solutions may be through $\mathrm{OH}$ radical and other Reactive Oxygen Species (ROS) generation. The addition of mannitol, catechin hydrate and tea solutions to the acids and photo Fenton solution mixtures all mitigated the negative effects of the duo on the cucumber plants. Mannitol at dosage applied in the present study can be adjudged to be the best in the amelioration of the negative effects of the fumigants. Future plant protection from deleterious impacts of atmospheric and hydrospheric pollutants can employ mannitol as scavengers of ROS.
\end{abstract}

Keywords: OH Radical, ROS, Acid Rain, Eco-Physiology, Scavengers

\section{Introduction}

Acid rain is a global environmental problem which can affect plants directly by suppressing the leaves function and indirectly by soil acidification and base cations leaching (Shu et al., 2019). Acid deposition may be in the form of acid rain, snow, fog, humidity and acid gas and dust (acidity $<\mathrm{pH}$ 5.6). Because human industrial activity produces additional acid-forming compounds in far greater quantities than natural sources of acidity, wet deposition with $\mathrm{pH}$ values of 3.0 or lower have been reported. Highly acidic deposition may cause many problems, ranging from killing freshwater fish and damage to crops, to erosion of buildings and monuments (Manahan, 2001). Additionally, acid deposition alters soil chemistry, nutrient availability and plant growth; thus, its effects on terrestrial ecosystems may be chronic and accumulative (Shan, 1998), leading to trees and shrubs being weakened and becoming more vulnerable to insects, diseases and fungal infestations (Eamus and Fowler, 1990; USEPA, 2010).

Acid mist at $\mathrm{pH} 2$ and 3 caused physiological and visual damage to Japanese red Pine (Oguntimehin et al., 2013). Zhang et al. (2020) indicated also that simulated acid rain at $\mathrm{pH} 3.5$ and $\mathrm{pH} 2.5$ could restrict photosynthesis and the antioxidant defense system, causing metabolic disorders and ultimately affecting plant development and growth. Moreover, vegetables and fruit trees were more sensitive to acid rain than other economically used plants (Du et al., 2017; Debnath et al., 2018).

There is increasing evidence that atmospheric pollutants caused elevated levels of Reactive Oxygen 
Species (ROS), which induced peroxidation of the cell membrane and contributed significantly to damage on plants (Shu et al., 2019).

Air pollutants, such as $\mathrm{O}_{3}$ and sulphur dioxide $\left(\mathrm{SO}_{2}\right)$, have been implicated in ROS formation and are considered to be one of the major factors contributing to modern forest decline (Langebartels et al., 2002). When cells are exposed to $\mathrm{SO}_{2}$ for example, an appreciable acidification of the cytoplasm occurs because this gas reacts with $\mathrm{H}_{2} \mathrm{O}$ to form sulphurous acid, which may then be converted into sulphuric acid. The oxidation of sulphite to sulphate in the chloroplast, which is initiated by light and mediated by photosynthetic electron transport, gives rise to $\mathrm{O}_{2} \cdot$.-

In plants, ROS are normal byproducts of various metabolic pathways, they are also produced under stress conditions in various cellular compartments, including chloroplasts, mitochondria, peroxisomes, the Endoplasmic Reticulum (ER) and plasma membranes (Mittler, 2002; Asada, 2006).

ROS production is controlled by various enzymatic and non-enzymatic antioxidative systems. Enzymatic antioxidants include catalase, CAT $\left(\mathrm{H}_{2} \mathrm{O}_{2}\right.$ oxidoreductase), Ascorbate Peroxidase (APX), Guaiacol Peroxidase (GPX), Superoxide Dismutase (SOD) and enzymes that detoxify LP products and non-enzymatic antioxidants include Ascorbic Acid (AA), Glutathione (GSH), Tocopherols (TOCs), Carotenoids (CARs) and phenolic compounds. In addition, an array of enzymes, such as Monodehydroascorbate Reductase (MDHAR), Dehydroascorbate Reductase (DHAR) and Glutathione Reductase (GR), is needed for the regeneration of the active forms of the antioxidants (Karuppanapandian et al., 2008; 2006a; 2006b; 2011).

ROS are not only produced as toxic by-products but are also an important component of the plant defense response during stress conditions. Generally, ROS have been proposed to affect stress responses in two different ways: ROS react with biological molecules causing irreversible damage that can lead to cell death (Karuppanapandian et al., 2011); and secondly, ROS influence the expression of several genes involved in various metabolic and signal transduction pathways (Mittler et al., 2004).

The objectives of this study were to investigate the effects of photo Fenton solution generating $\mathrm{OH}$ radicals, simulated acid rain and co-treatment with some exogenous scavengers of reactive oxygen species (i.e., mannitol, (+)-Catechin hydrate and tea solution) on cucumber plant (Cucumis sativus L. cv. Suyo) by the measurements of gas exchange characteristics, chlorophyll fluorescence parameters, chlorophyll values and foliar visible injury.

\section{Methodology}

\section{Plant}

Cucumber seedlings were purchased from a garden center in Saijo, Hiroshima Prefecture, Japan and were immediately transplanted into $10 \mathrm{~L}$ capacity growing pots. The pots contain the soil mixture "Golden" a vermiculite obtained commercially from Iris Ohyama Co. Ltd., Sendai, Japan. Plant growth and nurture took place inside greenhouses at the campus of Hiroshima University, Higashi-Hiroshima, Japan. For optimum growth, pots were watered once a day at 07:00 HR for 30 minutes using an auto-drip irrigation system installed inside the greenhouse. In addition, 'Hyponex-6-10-5' a liquid fertilizer (Hyponex Japan Corp. Ltd., NPK $=0.006 \%$ : 0.01\%:0.005\% solution) was used at a rate of $1 \mathrm{~mL}$ concentrated nutrient solution/500 mL water/pot weekly.

\section{Greenhouse Design}

Four greenhouse $(16 \mathrm{~m}$ length $\times 3 \mathrm{~m}$ width $\times 3 \mathrm{~m}$ height) chambers were used in plants cultivation, growth and nurture. The upper halves of the framed house (excluding the two ends) were covered with transparent Ethylene-Tetrafluoro Ethylene copolymer Film (ETFE) made by F-CLEANs, Asahi Glass Green-Tech Co. Ltd., Japan. The ETFE polymer allows maximum ultraviolet light transmission (over 95\% sunshine transparency) into the chamber. Observation showed that the meteorological conditions inside and outside the greenhouse during plant growth and the exposure periods were nearly same. Interestingly, mean air temperature and mean relative air humidity logged by a Thermo recorder TR-72S (T\&D Corp., Japan) in the greenhouse from April to July were $25.8 \pm 2{ }^{\circ} \mathrm{C}$ (day); $19.1 \pm 2{ }^{\circ} \mathrm{C}$ (night) and $71.2 \pm 5 \% \mathrm{RH}$ respectively. Likewise, mean photosynthetic photon flux density (PPFD) measured using an LI-190SA Quantum Sensor (Licor, USA) at noon on most sunny days during the experimental period via the foliage of the cucumber plants was $1107 \pm 26 \mu \mathrm{mol} \mathrm{m}{ }^{-2} \mathrm{~s}^{-1}$.

\section{Treatments and Exposure}

The treatments used in the present research can be classified generally into three types. Type I are the one containing the $\cdot \mathrm{OH}$-generating solution-R; Type II are those containing the sulphuric acid mist- $\mathrm{S}$ and the Type III are the various additives used for various purposes. Altogether, four treatments were used in each category, making the total number of treatments twelve.

The $\mathrm{OH}$ generating solution (R) known as photo Fenton solution (Chiwa et al., 2005; OH formation rate $11.6 \mu \mathrm{M} / \mathrm{h}$ ) was prepared from (Hydrogen peroxide $200 \mu \mathrm{mol} / \mathrm{L}+$ Iron(III) chloride $1 \mu \mathrm{mol} / \mathrm{L}+$ Sodium oxalate $5 \mu \mathrm{mol} / \mathrm{L}$ ).

A stock solution of $0.1 \mathrm{M} \mathrm{H}_{2} \mathrm{SO}_{4}(\mathrm{~S}$; Nacalai Tesque Inc., Kyoto, Japan) was prepared by adding $1.53 \mathrm{~mL}$ of the acid into $100 \mathrm{~mL}$ of Milli-Q water (ultra-pure water 
obtained from a MilliQ Plus system, Japan, Millipore; $\geq$ $18 \mathrm{M} \Omega \mathrm{cm}$ ) in a standard flask. The stock was diluted to a final $\mathrm{pH}$ of 3 with MilliQ water inside a $2 \mathrm{~L}$ beaker for each spraying period.

Mannitol (M) and (+)-Catechin hydrate (C) at a concentration of $1 \mathrm{mM}$ and $100 \mu \mathrm{mol} / \mathrm{L}$ (Tokyo chemical industry Co., LTD, Japan), respectively were prepared for use as $\mathrm{OH}$ radical scavengers. Moreover, $2 \mathrm{~g}$ of tea leaves (Safari tea) were added to $150 \mathrm{~mL}$ of MilliQ water of $30^{\circ} \mathrm{C}$ for $2 \mathrm{~min}$ then filtered using $0.45 \mu \mathrm{m}$ membrane filter to get tea solution (T). The twelve experimental treatment groups were given acronyms as; R, RM, RC, RT, S, SM, SC, ST, M, C, T and the CO (Con.; cucumber plants fumigated with MilliQ water only).

Each treatment group was made up of six cucumber plants distributed carefully inside the greenhouse. All the sprayed treatment solutions were applied to cucumber foliage three times per week (day after two days at 07:00-08:00 HR) from May 23 to July 4 using an electronic spray machine with a nozzle (BS-4000, Fujiwara Sangyo, Miki, Japan). On the average, each plant received about $50 \mathrm{~mL}$ of solution per spraying period (42d) and the solutions' components were applied singly. In most cases, $\mathrm{S}$ or $\mathrm{R}$ were fumigated first and the other components e.g. $\mathrm{M}$ in SM treatment; $\mathrm{C}$ in $\mathrm{SC}$ treatment and $\mathrm{T}$ in ST treatment were applied after the wet cucumber leaves had become dried naturally after 30 min (Oguntimehin et al., 2010a). Visible injury of cucumber leaves was observed across all treatments.

\section{Gas Exchange Measurements}

Carbon dioxide and water vapor exchange measurements were conducted on mature primary cucumber leaves as previously reported by Oguntimehin et al. (2010b). From 7:00 to 11:00 HR, net photosynthesis $\left(A_{\max }\right)$ at near-saturating irradiance of $1500 \mu \mathrm{mol} \mathrm{m} \mathrm{m}^{-2} \mathrm{~s}^{-1}$, stomatal conductance $\left(g_{s}\right)$ and intercellular $\mathrm{CO}_{2}$ concentration $\left(C_{i}\right)$ were measured in matured leaves in each treatment. For each measurement, the leaf chamber area was fully covered with cucumber leaf. Chamber leaf temperature was kept at $25 \pm 2{ }^{\circ} \mathrm{C}$ while the leaf to air vapor pressure deficit' (VpdL) was maintained between 0.8 and $1.3 \mathrm{kPa}$ and 'air into leaf chamber' $\mathrm{CO}_{2}$ concentration was kept at $370 \mu \mathrm{mol} \mathrm{CO}_{2}$ $\mathrm{mol}^{-1}$ in a flow rate of $500 \mu \mathrm{mol} \mathrm{s} \mathrm{s}^{-1}$ by an open-flow infrared gas analyzer with light and temperature control systems (LI-6400, Li-cor Inc., Lincoln, NE, USA).

\section{Chlorophyll Fluorescence}

Chlorophyll fluorescence was measured at 19:3020:30 HR using a portable chlorophyll fluorometer (MINI-PAM, Heinz Walz GmbH, Effeltrich, Germany) with leaf-clip holder 2030B (Heinz Walz $\mathrm{GmbH}$ ); and a micro quantum sensor for selective photosynthetically active radiation (PAR) measurements ( 0 to $20,000 \mu \mathrm{mol}$ $\left.\mathrm{m}^{-2} \mathrm{~s}^{-1}\right)$. The leaves that were previously used for the leaf gas exchange measurements were dark-adapted and arranged compactly in a parallel array and clamped with the holder, then the minimal fluorescence values $\left(F_{o}\right)$ were obtained upon excitation of leaves with a beam from the light-emitting diode; and maximum fluorescence $\left(F_{m}\right)$ was measured following a $600 \mathrm{~ms}$ pulse of saturating white light. The yield of variable fluorescence $\left(F_{v}\right)$ was taken as $F_{m}-F_{o}$. These measurements indicated maximal photochemical efficiency of PS (II) in the dark $\left(F_{v} / F_{m}\right)$.

\section{SPAD Leaf Chlorophyll Value Measurements}

Chlorophyll content value in cucumber leaves (5 leaves per plant) was estimated by using a digital chlorophyll meter SPAD (Model 502, Konica Minolta Optics Inc., Osaka, Japan) through measuring light absorption by leaves at specific wavelengths. The measurements were carried out a day before the treatment applications and immediately after the treatments finished. The measurements were recorded in Chlorophyll meter (Soil Plant Analysis Development 'SPAD') units (Markwell et al., 1995; Oguntimehin et al., 2010b). The difference between the readings before and after the treatments is an index of leaf or plant health.

\section{Statistical Analysis}

The SPSS 16 (SPSS, USA) software was used to analyze all data. Results were presented as averages of values from six cucumber plants in each treatment group. The significance of the differences in average values among treatments was evaluated by ANOVA after verifying normality and homogeneity of the data (one-way ANOVA, $p<0.05$ ). Comparison of means between the treatments was performed using Tukey's post-hoc treatment test.

\section{Results}

\section{Photosynthetic Responses in Cucumber Plants to Varied Treatment Types}

Respiration used to compliment photosynthesis in higher plants. The primary function of photosynthesis is to assimilate $\mathrm{CO}_{2}$ and radiant energy in the formation of carbohydrate. A significant portion of those carbohydrates become the main substrates of respiration, but often after some period of storage or distance of transport (Amthor, 1995). The present study shows values for the photosynthetic rate at maximum irradiance $\left(\mathrm{A}_{\max }\right)$, which are different statistically when compared between varied treatment types. Negative effect of some treatments on plant becomes very strikingly noticed for the S, R treatments, whose values are about $75 \%$ and $55 \%$ reduced as against the control $(\mathrm{Co})$. Other treatment used to control the negative impact of each target stress-inducing treatment and to suggest a form of amelioration were higher in values than treatments $S$ and R, respectively (Fig. 1A). 
It is an established truth that the most physiologically meaningful measure of stomatal functioning is the diffusion resistance or (conductance) Jones (1994). So also, since many individual factors have notably high effects on stomatal conductance, it has been best studied under a controlled environment as used in the present study where each factor may be varied independently. Results of $\mathrm{g}_{\mathrm{s}}$ from the present study closely mimics the $A_{\max }$, in that treatments containing acidic (S) and the hydroxyl radical $(\mathrm{R})$ are statistically and comparatively lower in value than the control (Co).
Since the internal $\mathrm{CO}_{2}$ concentration determined in the present study relates to that fixed in the photosynthesis, it must diffuse from the ambient air through a series of resistances to the carboxylation site, there is usually a fairly constant values recorded for the majority of the treatments unlike what was observed for the $\mathrm{A}_{\max }$ (Oguntimehin and Sakugawa, 2008; Oguntimehin et al., 2013). As shown in Fig. 1C, there is an obvious inverse correlation relationship between $\mathrm{A}_{\max }$ and interstitial $\mathrm{CO}_{2}$ concentration. Table 1 depicts that elevated $\mathrm{CO}_{2}$ concentration had a significantly lowered effects on both $\mathrm{A}_{\max }$ and $\mathrm{g}_{\mathrm{s}}$.
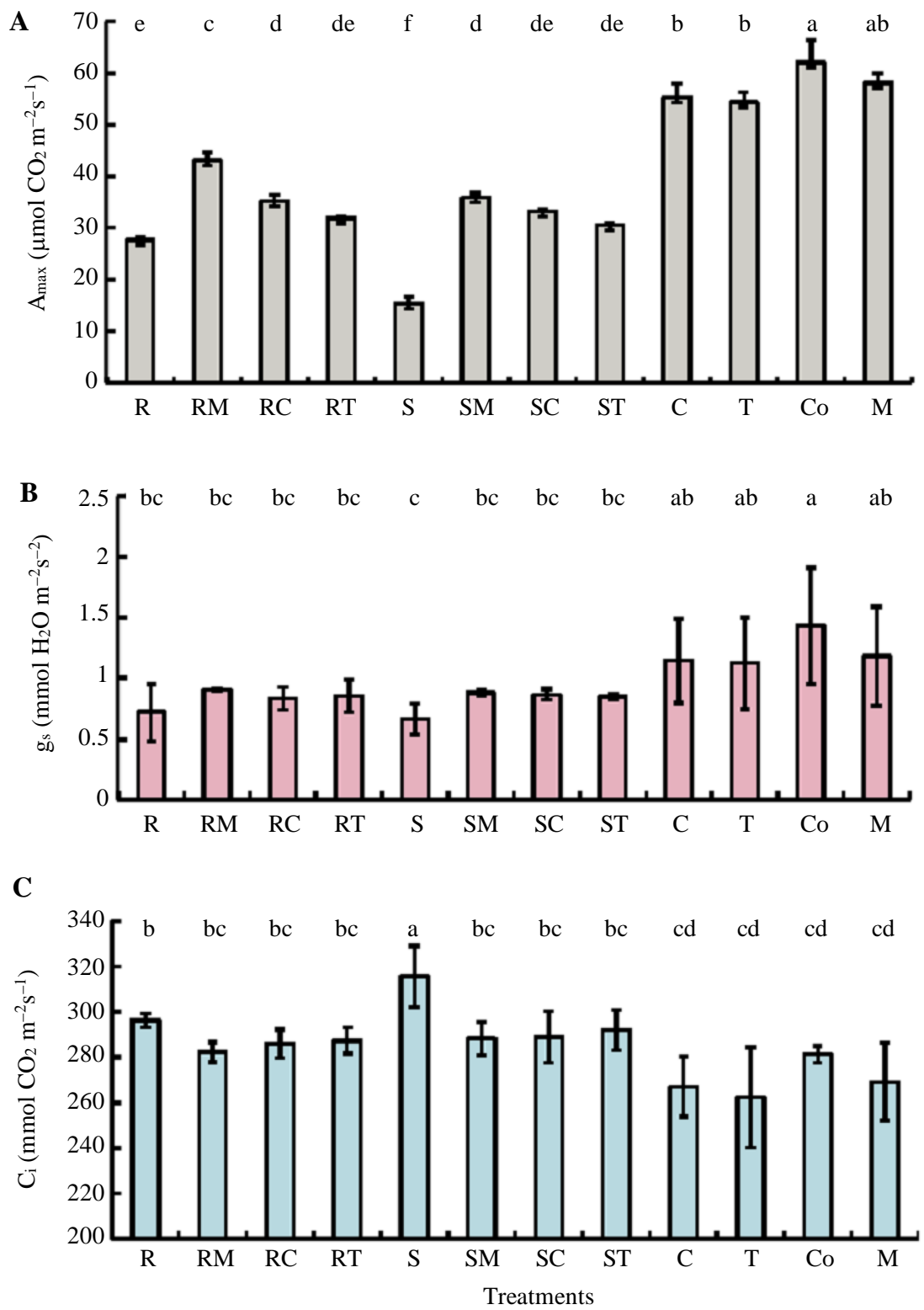

Fig. 1: (a) The photosynthetic rate measured at saturated irradiance, $A_{\max }$. (b) Stomatal conductance to water vapor, $g_{s}$. (c) Internal $\mathrm{CO}_{2}$ concentration, $C_{i}$, for twelve treatments of cucumber, including a control measured after the 42 days exposure. Values shown in the figure are means of six plants measurement in each treatment group \pm standard errors. Different letters on each bar indicate significant differences for a treatment at $\mathrm{p}<0.05$ 


\section{Basic Chlorophyll Measurement Responses to the Simulated Plant Stressor}

The results of the cucumber leaves chlorophyll fluorescence analysis is a reflection of the functioning of the intact photosynthetic system. Minimum fluorescence $\left(\mathrm{F}_{\mathrm{o}}\right)$ is the intensity of fluorescence divided by the intensity of the light used to excite fluorescence. $F_{0}$ was measured when all reaction centres are in oxidized or open state. $F_{o}$ values obtained in the present study were fairly uniform for almost all the treatments. Slight elevation in values was noticeable for $\mathrm{R}$ as against the $\mathrm{M}$ treatment. $\mathrm{S}$ treatment does not show much elevation in $F_{o}$ value like $R$ treatment. The maximum fluorescence $\left(\mathrm{F}_{\mathrm{m}}\right)$ is an important indication of an irreversible or partially slowly reversible damage to the photosynthetic system in plants. The results as shown in Fig. 2B indicated that $\mathrm{F}_{\mathrm{m}}$ is drastically lowered and statistically significant in the two treatments $\mathrm{R}$ and $\mathrm{S}$.
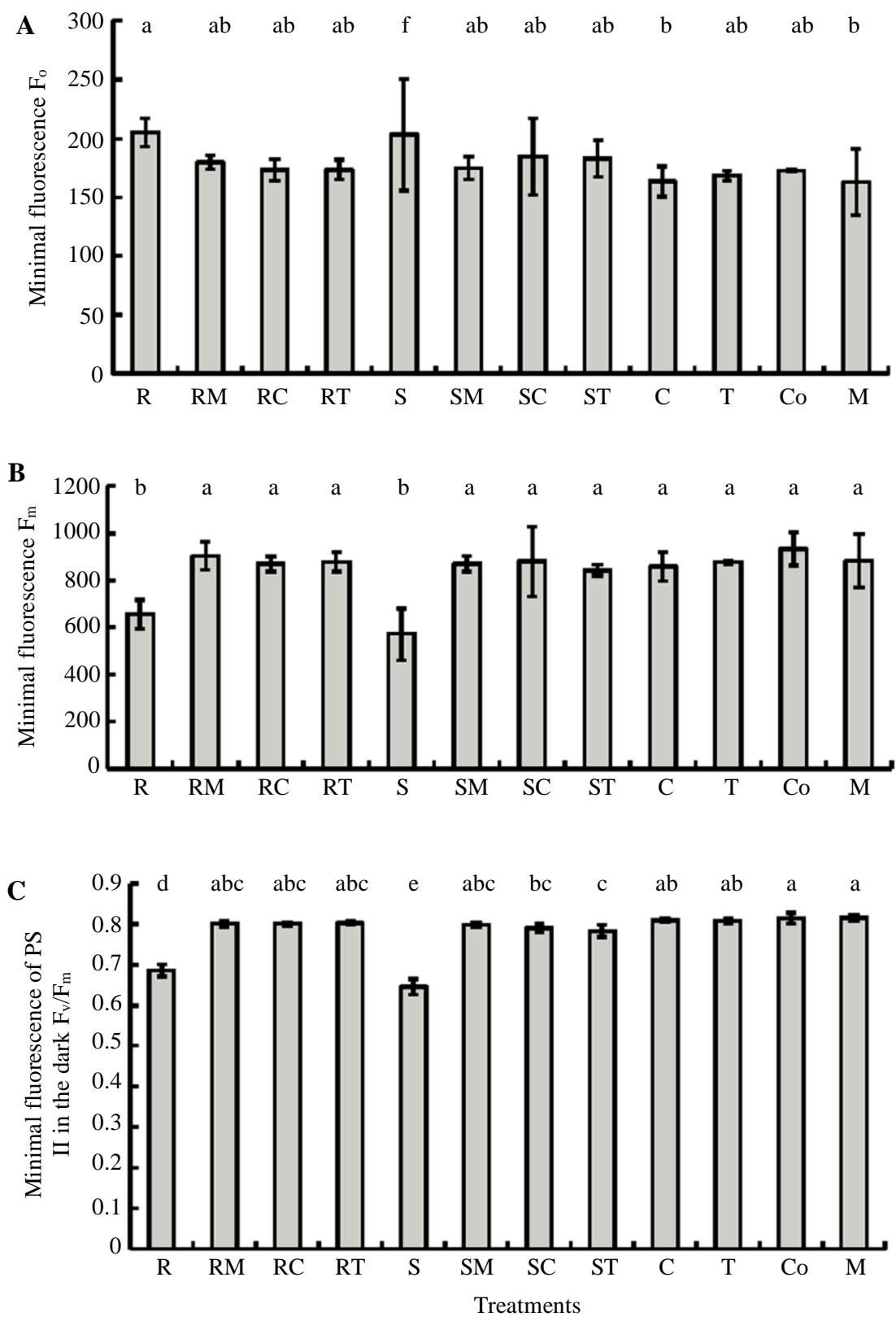

Fig. 2: (a) Initial fluorescence, $F_{0}$. (b) Maximum fluorescence, $F_{m}$. (c) Photochemical efficiency of PSII in the dark, $F_{\mathrm{v}} / F_{\mathrm{m}}$ for twelve treatments of cucumber, including a control measured after the 42 days exposure. Values shown in the figure are means of six plants measurement in each treatment group \pm standard errors. Different letters on each bar indicate significant differences for a treatment at $\mathrm{p}<0.05$ 
Photoinhibition is often related to a particular quenching that controls the lowering of $\mathrm{F}_{\mathrm{m}}$ values, however, more than just lowering in the Fo value, a more and better efficient assessment of plant stress in plants is the efficiency of PS II in the dark given by the ratio $F_{v} / F_{m}$. The values of $F_{v} / F_{m}$ were fairly stable in all the treatments and close to the estimated normal value of 0.83 proposed for a healthy plant (Bjorkman and Demmig, 1987). However, unlike the healthy value, those for the $\mathrm{R}$ and $\mathrm{S}$ treatments are below 0.7. Those values are even smaller compared with our previous studies reported on some treated higher plants (Cherry tomato and Japanese red pine seedlings (Oguntimehin et al., 2010a; 2013). However, results of the acid and reactive oxygen generation treatments on $\mathrm{F}_{\mathrm{v}} / \mathrm{F}_{\mathrm{m}}$ are much more comparable to that from another earlier study using an Impatiens spp. as bioindicator of ozone, fluoranthene and acid exposure (Oguntimehin et al., 2010b).

\section{The Cucumber Leaf Chlorophyll Quality and Visual Assessment Variations with Treatments}

The cucumber SPAD chlorophyll value is a characteristic of the amount of chlorophyll in the cucumber leaves. The SPAD value is a measure of the absorbances in the red and the near-infrared regions. Using the two absorbances, the numerical SPAD value is proportional to the amount of chlorophyll in the leaves.

The present study results indicated that the cucumber plants treated with acid or acid-containing treatments $(\mathrm{S}$, SM, SC and ST) have very poor leaf chlorophyll values (Fig. 3). The lowest being the $\mathrm{S}$ treatment which is about $57.6 \%$ decreased when compared to the control treatment 'Co'. Similar poor leaf Chlorophyll values were recorded for treatments ( $\mathrm{R}, \mathrm{RM}, \mathrm{RC}$ and $\mathrm{RT})$. The treatments type containing $\mathrm{OH}$ radical producing mixtures with ' $\mathrm{R}$ ' being the mostly phytotoxic in the treatment group. It was observed to have a reduced SPAD chlorophyll value of about $50.6 \%$ compared to the control treatment ' $\mathrm{Co}$ '.

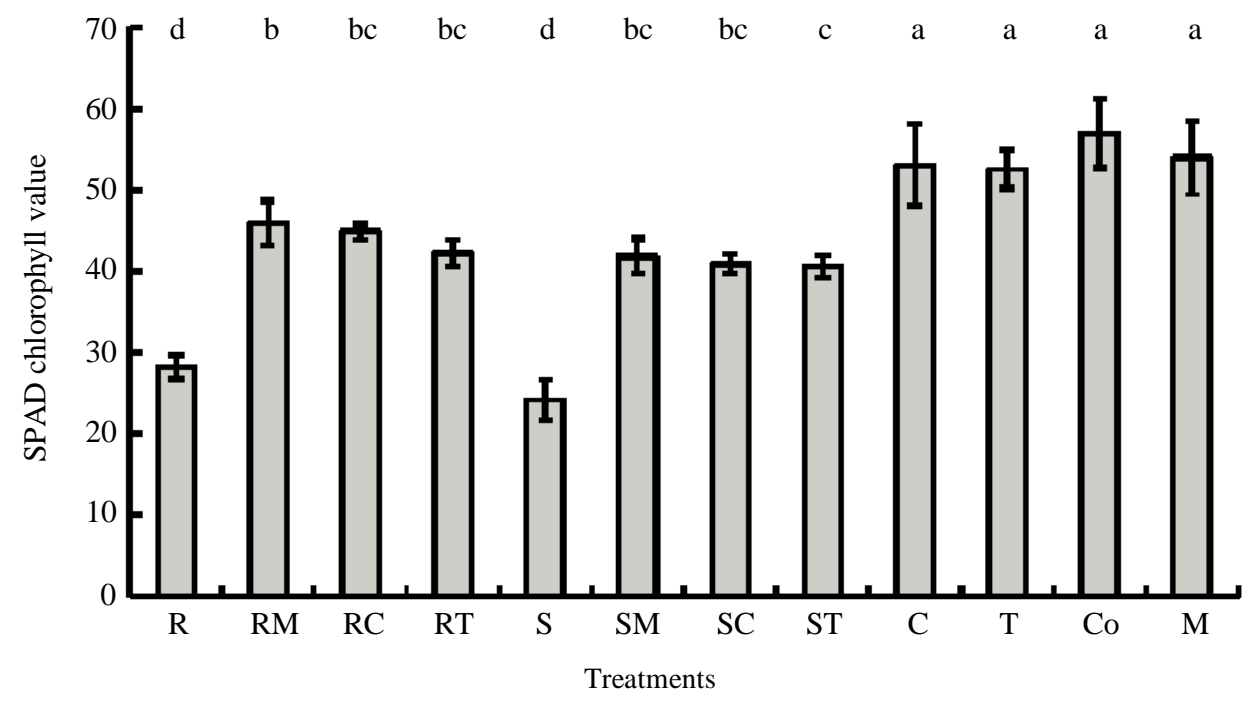

Fig. 3: SPAD Chlorophyll value of cucumber plant leaves under twelve treatments measured after the 42 days exposure. Values shown in the figure are means of six plants measurement in each treatment group \pm standard errors. Different letters on each bar indicate significant differences for a treatment at $\mathrm{p}<0.05$.

Table 1: The Correlation relationships (Pearson Correlation) of the Eco-physiological traits of the treated cucumber leaves after $42 \mathrm{~d}$ period Pearson correlation

\begin{tabular}{lllllll} 
& $\mathrm{A}_{\max }$ & $\mathrm{g}_{\mathrm{s}}$ & $\mathrm{C}_{\mathrm{i}}$ & $\mathrm{F}_{\mathrm{o}}$ & $\mathrm{F}_{\mathrm{m}}$ & $\mathrm{F}_{\mathrm{v}} / \mathrm{F}_{\mathrm{m}}$ \\
\hline $\mathrm{A}_{\max }$ & 1 & & & & & \\
$\mathrm{~g}_{\mathrm{s}}$ & $0.716^{* *}$ & 1 & & & & \\
$\mathrm{C}_{\mathrm{i}}$ & $-0.705^{* *}$ & $-0.418^{*}$ & 1 & & & \\
$\mathrm{~F}_{\mathrm{o}}$ & $-0.520^{* *}$ & $-0.338^{*}$ & $0.396^{*}$ & 1 & & \\
$\mathrm{~F}_{\mathrm{m}}$ & $0.569^{* *}$ & $0.389^{*}$ & $-0.530^{* *}$ & -0.096 & 1 & \\
$\mathrm{~F}_{\mathrm{v}} / \mathrm{F}_{\mathrm{m}}$ & $0.715^{* *}$ & $0.462^{* *}$ & $-0.632^{* *}$ & $-0.621^{* *}$ & $0.830^{* *}$ & 1 \\
$\mathrm{CC}$ & $0.917^{* *}$ & $0.615^{* *}$ & $-0.697^{* *}$ & $-0.515^{* *}$ & $0.746^{* *}$ & $0.857^{* *}$ \\
\hline
\end{tabular}

\footnotetext{
$* *$. Correlation is significant at the 0.01 level (2-tailed)
}

*. Correlation is significant at the 0.05 level (2-tailed). 
The pictures of the cucumber plant leaves for the various treatment types after the long-term exposure experiments are displayed as Pic. 1a to Pic. 3c (Fig. 4). The Pic 1a and Pic 2a belonging to the photo Fenton solution and the acid solution treated cucumber plants

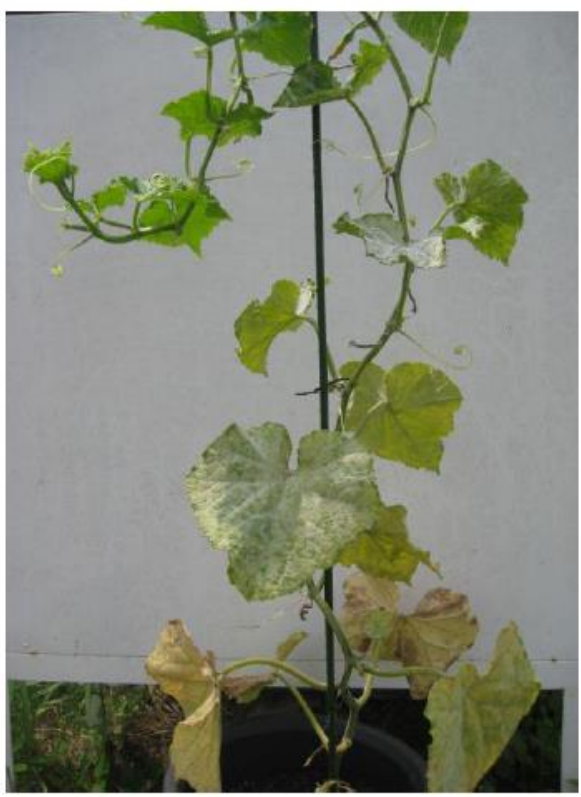

Pic. 1a: ' $R$ ' treatment

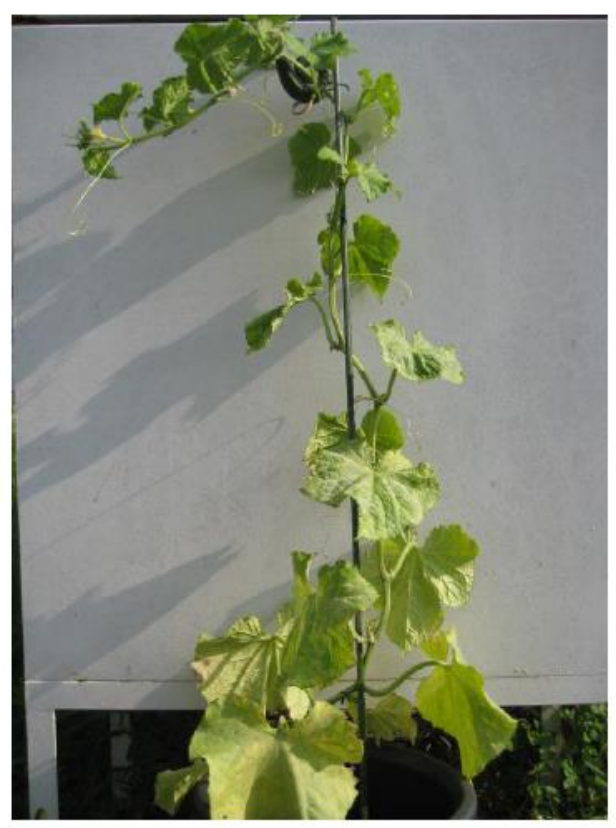

Pic. 1c: 'RT' treatment have the highest concern as visible foliar damages like chlorosis and necrosis are highly presented. Other in the control group and mannitol solution treated plants are safe and have reduced or no negative foliar symptoms of disease and malady.

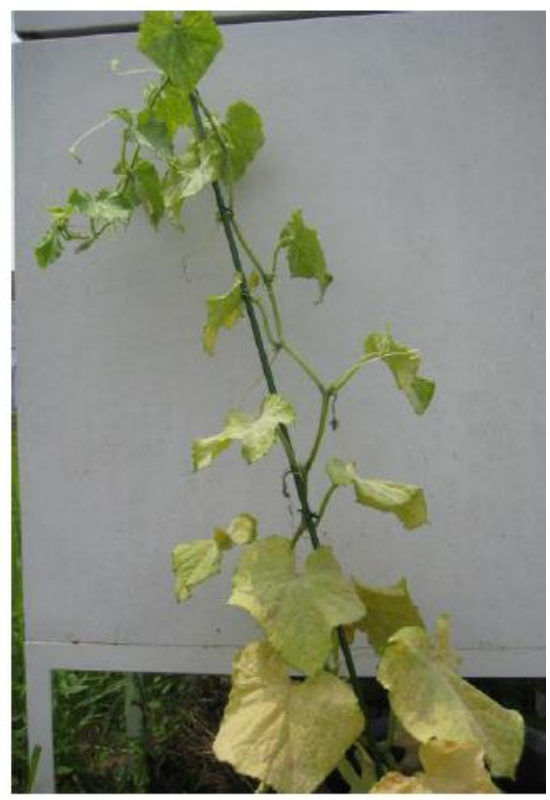

Pic. 1b: 'RC' treatment

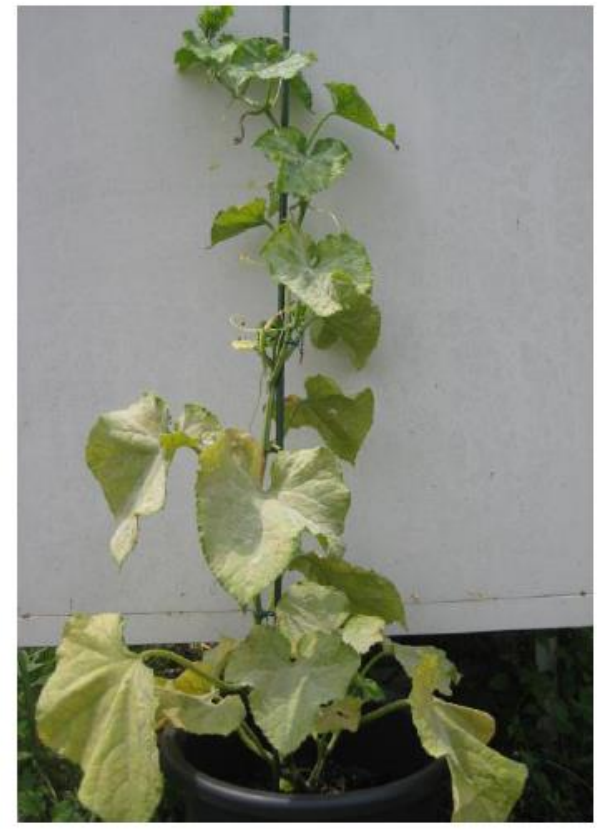

Pic. 1d: 'RM' treatment 


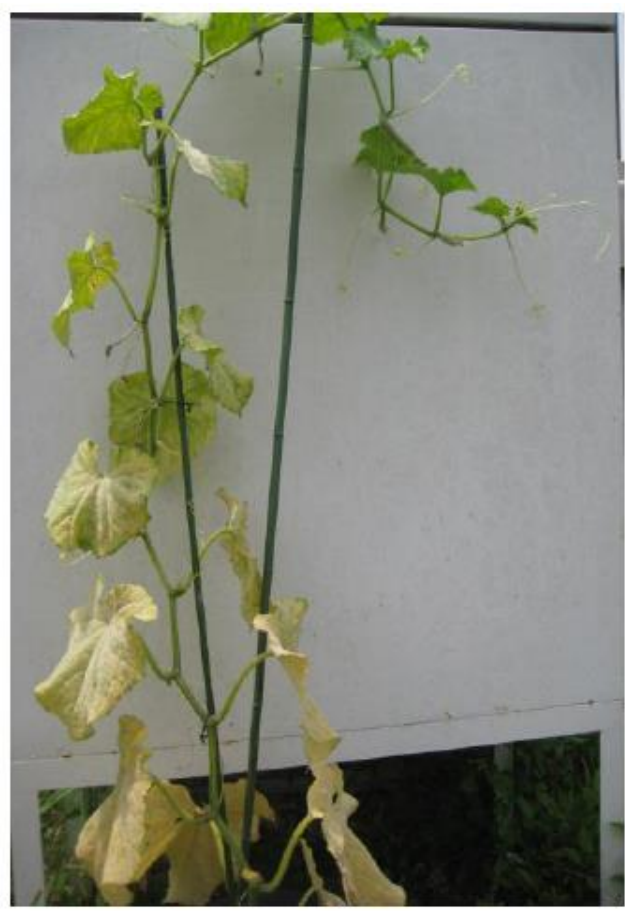

Pic. 2a: ' $S$ ' treatment

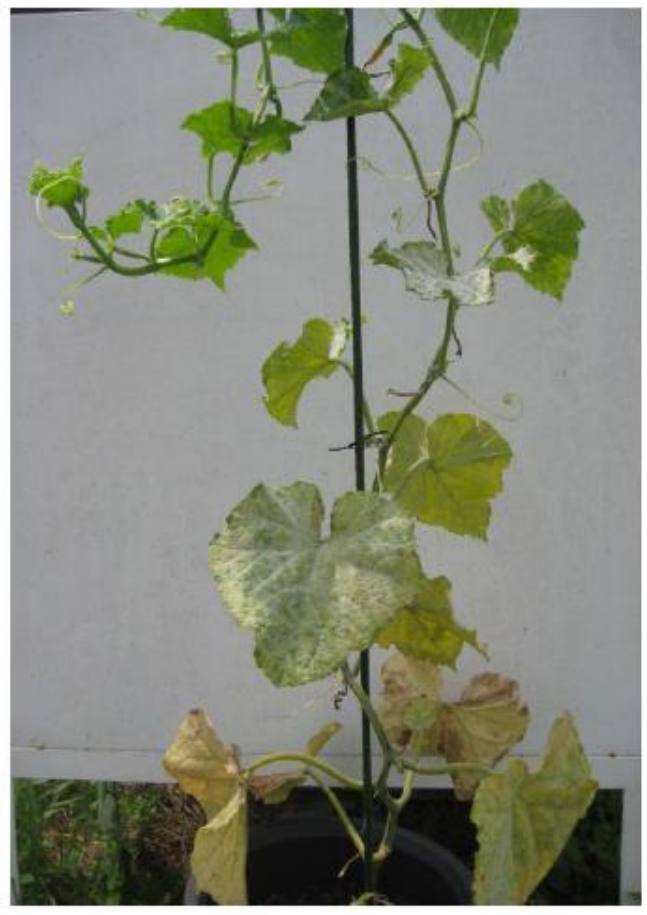

Pic. 2c: 'ST' treatment

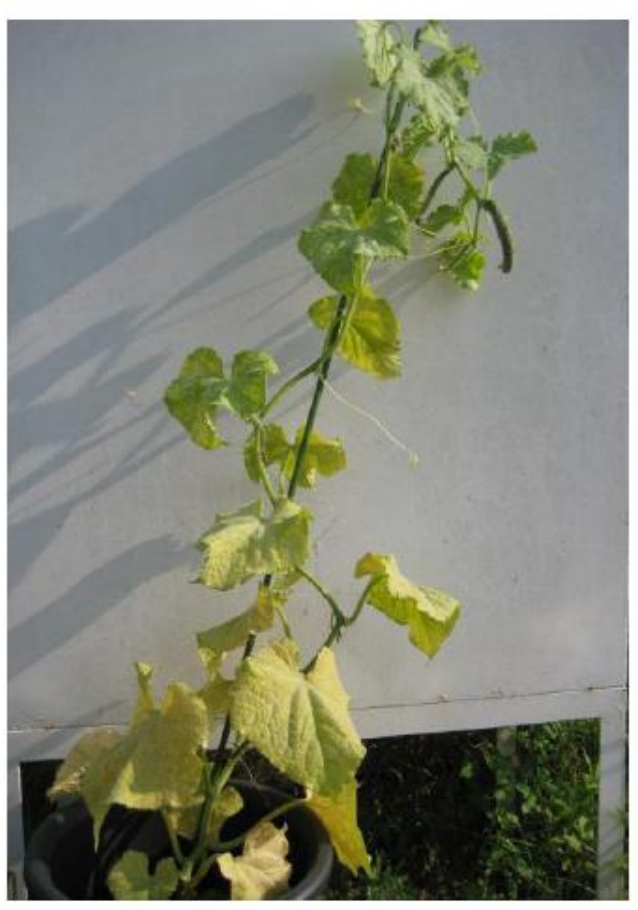

Pic. 2b: 'SC' treatment

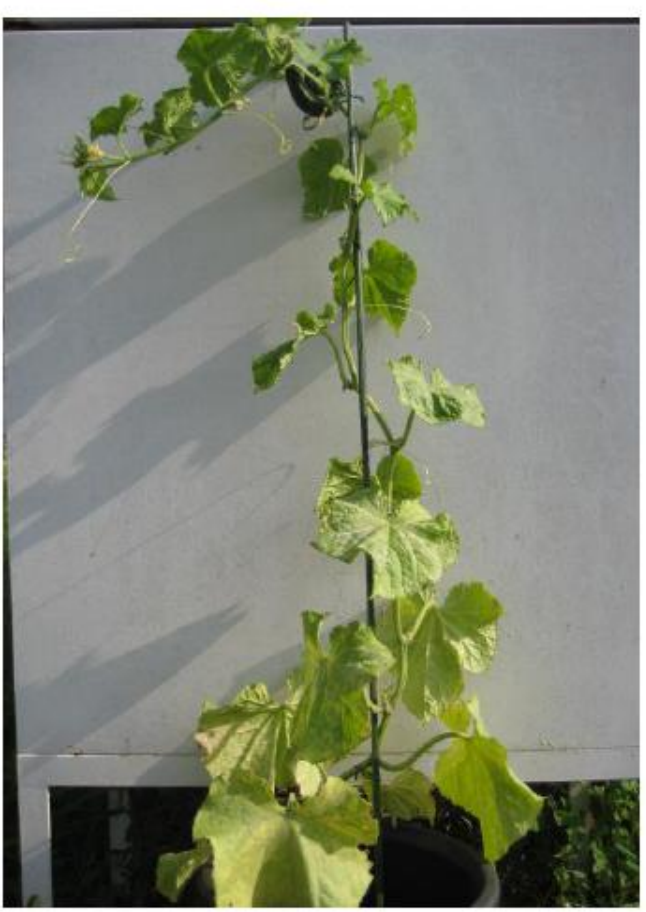

Pic. 2d: 'SM' treatment 


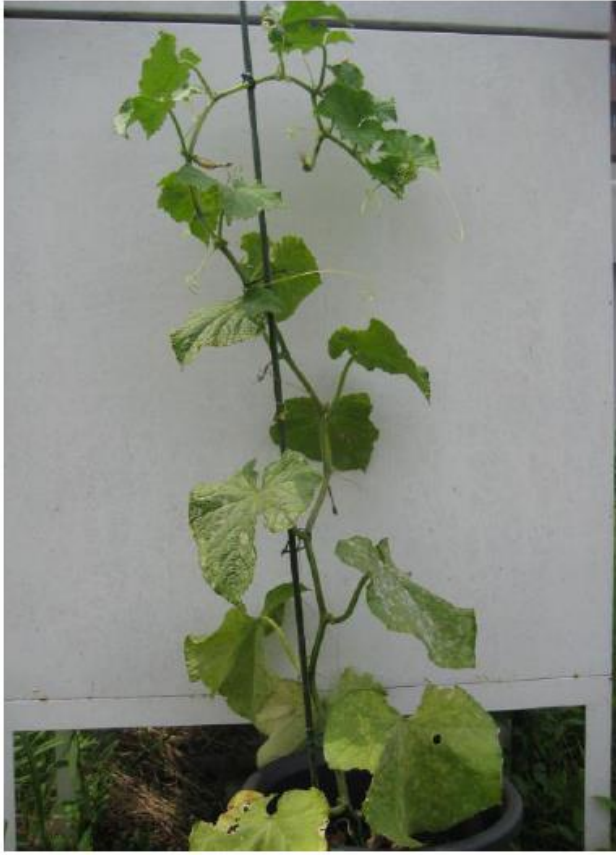

Pic. 3a: 'C' treatment

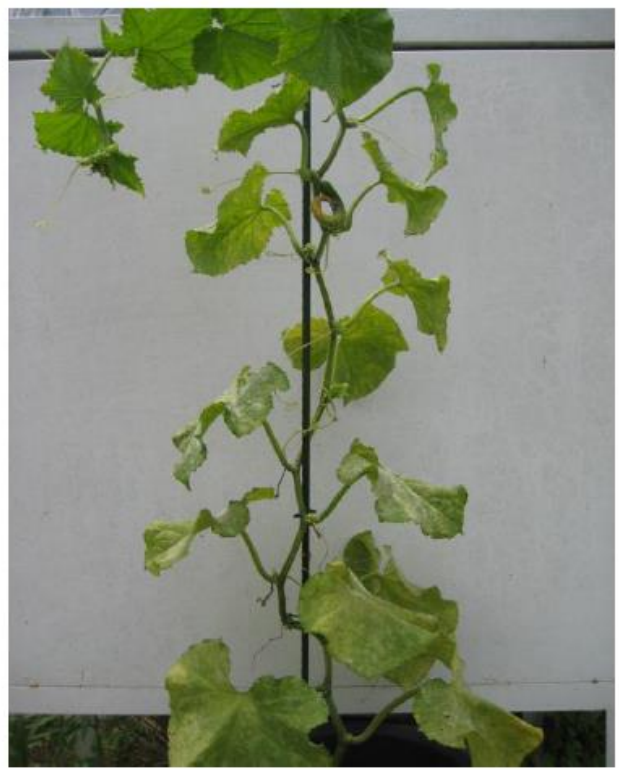

Pic. 3c: 'Co' treatment

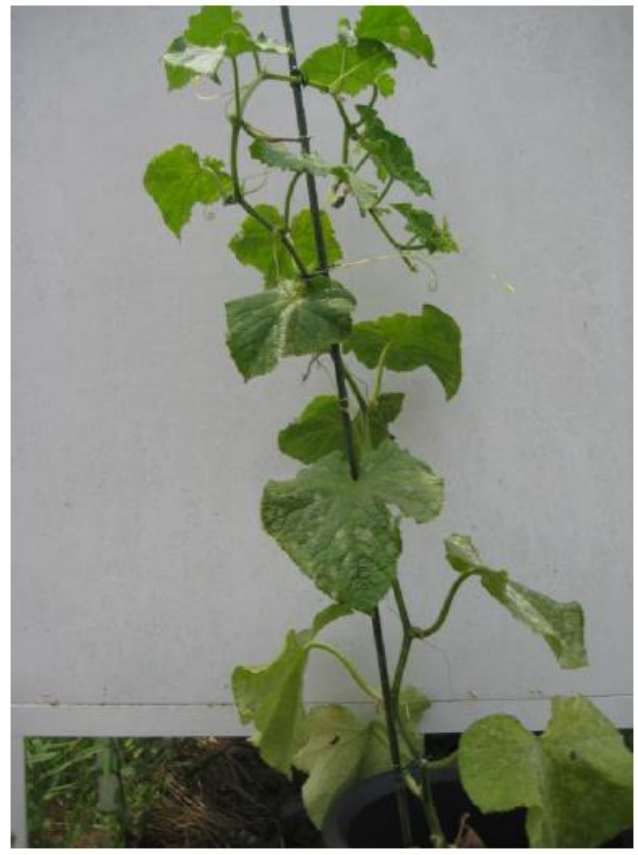

Pic. 3b: ' $T$ ' treatment

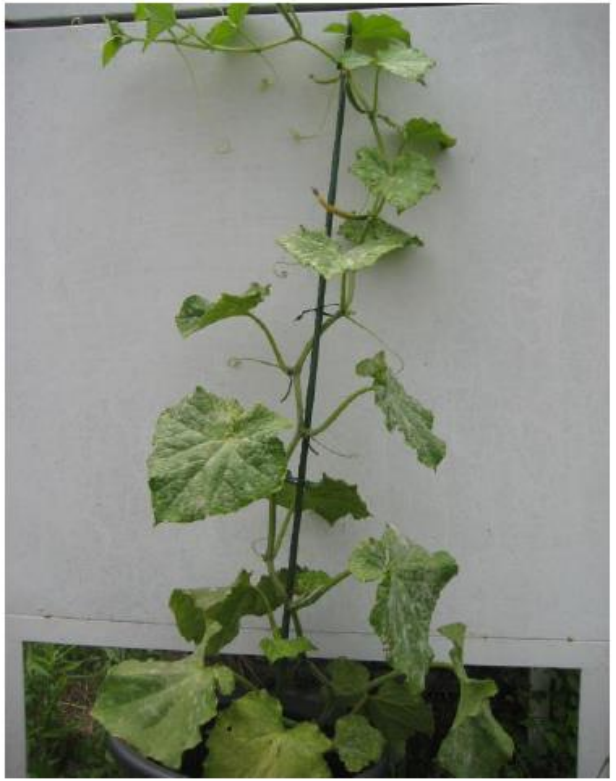

Pic. 3d: Mannitol

Fig. 4: Leaf visible foliar damage as contrasted between the three types treatments: Type $\mathrm{I}$ are the one containing the $\cdot \mathrm{OH}-$ generating solution-R, R plus Mannitol (RM), R plus catechin hydrate (RC) and R plus Tea solution (RT).; Type II are those containing the sulphuric acid mist-S, S plus Mannitol (SM), S plus catechin hydrate (SC) and S plus tea solution (ST); and the Type III are mannitol (M), catechin hydrate (C), tea solution (T) and control (CO); Picture 1(a-d) showing the foliar symptoms from the photo Fenton Solution (R) containing treatments; Pic. 2(a-d) showing the foliar symptoms from the Sulphuric acid (S) containing treatments; Pic. 3(a-d) showing the foliar symptoms from the different controls' treatments 


\section{Discussion}

\section{Negative Impact of Acidic and Reactive Oxygen Species on Cucumber Plant Gas Exchange}

The lower photosynthetic rate $\left(\mathrm{A}_{\max }\right)$ measured for the acid and $\mathrm{OH}$ radical producing reagent mixtures treated cucumber plants are indications of inhibition in photosynthetic apparatus and the resultant poor health conditions conferred on the plants in the short term exposures.

The various combinations of the acid and $\mathrm{OH}$ radical producing mixtures were found to have an ameliorating effect on negative implications on the cucumber plants. Mannitol as additive to these treatments manifested the greatest mitigation activities for both the acid and the $\mathrm{OH}$ radical mix. This observation corroborates earlier studies involving using different treatment mists on Japanese red pine seedlings and cherry tomato plants (Nakatani et al., 2004; Oguntimehin and Sakugawa, 2008; Oguntimehin et al., 2010a; 2010b). Other additives added to the fumigants also have similar mitigating effects.

Stomatal closure is an important stress avoidance mechanism in plants (Lefohn, 1991). The reduction in $\mathrm{A}_{\max }$ and gs of treated cucumber plants by the acid and photo Fenton solution in the current study are comparable to older results obtained by Kobayashi et al. (2002; Yoon et al., 2006), who fumigated with $\mathrm{OH}$ radical-generating solutions on Japanese red pine and Japanese apricot (Prunus mume) plants, respectively.

A different but more recent study involving the use of photo Fenton solution similar to the $\mathrm{OH}$ generating mixture employed in the present study has established the ability of such mix to impact the protective effect of the cucumber plant against the popular disease 'powdery mildew' (Sakugawa et al., 2012). The present study has been able to show that increased dosage of photo Fenton solution over the amount experimented with the previous study on the plants may be deleterious to cucumber plants. This sancrosanctly place a caution on the dosage of exposure of photo Fenton solution and the likes known to operate via the production of $\mathrm{OH}$ radical or other Reactive Oxygen Species (ROS) generation for preventive or curative purposes on plants.

The decreased $A_{\max }$ and $g_{s}$ are highly connected to each other (Table 1). There is a possibility of formation of ROS outside the plant, on the leaves of cucumber directly from the $\mathrm{OH}$ generation mixtures. This may eventually find its way inside the plant through the stomata opening into the chloroplast, thereby causing photoinhibition and photooxidation. It has been earlier established that a more complex process for the generation of ROS may also take place inside the plants (Karuppanapandian et al., 2006c). The amount of ROS produced in the plant is therefore increased by the treatment source. Most reliably, the decreased effect of $\mathrm{g}_{\mathrm{s}}$ in this present study might have caused the decreased $\mathrm{A}_{\max }$ values. Stomata resistance, likened to resistance of boundary layers, is directly linked to the diffusion of the pollutant plume through the stomata. Another possibility is the ROS inhibiting the activity of sulphuric acidcontaining, light-activated enzymes of the chloroplast, thereby resulting in the loss of photosynthetic function (Vollenweider et al., 2003).

$\mathrm{C}_{\mathrm{i}}$ represents a balance of $\mathrm{CO}_{2}$ influx through the leaves via the stomata aperture $\left(\mathrm{g}_{\mathrm{s}}\right)$. Even though the $\mathrm{CO}_{2}$ concentration in the environment is relatively constant, stomata are sensitive to $\mathrm{CO}_{2}$. The nearly stable internal $\mathrm{CO}_{2}$ concentration in this study is not strange (Oguntimehin et al., 2010b). Ultimately, the close matching of $g_{s}$ with $A_{\max }$ must have suggested that a signal from the mesophyll controls the stomatal aperture (Jones, 1994).

\section{Chlorophyll Fluorescence Response in Treated Cucumber Plants}

Photosystem II oxidizes water to evolve oxygen and provides electrons and protons. The energy is conserved in unstressed plants. However, under stress induction, there is a loss in energy due to the rapid disappearance of PS II subunits and the stalling of photosynthesis. Photoinhibition is therefore increased under stress conditions (Trebst, 1995). The highly reduced values of $\mathrm{F}_{\mathrm{v}} / \mathrm{F}_{\mathrm{m}}$ below the generally accepted value 0.83 (Bjorkman and Demmig, 1987) for a healthy plant in the dark-adapted plants is a clear indication of extremely stressed cucumber plants from the $\mathrm{R}$ and $\mathrm{S}$ treated groups. Lowered values of the quantum yield falling below 0.7 may be traceable to the damage done by photoinhibition to the PS II system thereby lowering its ability to transport electron functionally (Navrot et al., 2007).

\section{Factors that Impacted Photosynthetic Activities in Treated Cucumber Leaves}

All eco-physiological parameters determined in the present study impacted either positively or negatively on the photosynthesis of cucumber plant. The overall effect of tampering with the photosynthetic pathway, apparatus and rate will ultimately contribute to plant increased or decreased plant health. The study has been able to show (Table 1) that parameters of positive correlations with $\mathrm{A}_{\max }$ are chlorophyll content $(\mathrm{CC})>$ leaf stomatal conductance $\left(\mathrm{g}_{\mathrm{s}}\right)>$ efficiency of PSII in the dark $\left(\mathrm{F}_{\mathrm{v}} / \mathrm{F}_{\mathrm{m}}\right)>$ maximum fluorescence value $\left(\mathrm{F}_{\mathrm{m}}\right)$. On the contrary, the parameters internal $\mathrm{CO}_{2}$ concentration $\left(\mathrm{C}_{\mathrm{i}}\right)$ and initial fluorescence value $\left(\mathrm{F}_{\mathrm{o}}\right)$ are negatively correlated with $\mathrm{A}_{\max }$. The very high correlation coefficent between $\mathrm{A}_{\max }$ and $\mathrm{CC}$ is a reflection of how the health status of plants with green leaves (high chlorophyll) could mean better 
photosynthetic apparatus and consequently high photosynthetic rate. Other parameters observed with such high correlations with $\mathrm{A}_{\max }$ is in agreements with some previous studies (Oguntimehin and Sakugawa, 2008; Oguntimehin et al., 2010a; 2010b). The obvious fact that plants health status can be directly linked to its $\mathrm{A}_{\max }$ output can never be overemphasized.

\section{Comparative Phytotoxicity of Acid and Photo Fenton Solution}

Clearly, the study has been able to comparatively examine the impact of acid rain and the photo Fenton solution on the cucumber plant. The phytotoxicity of the two are significantly observed with respect to the decreased gas exchange parameters (photosynthetic rates, stomatal conductance), physiological changes as reflected by the lowered SPAD chlorophyll quality of the cucumber leaves and the poor foliar appearances of the two treatment groups. It can be boldly said that the acids group inflicted more injuries and general damages to the cucumber plant than the $\mathrm{OH}$ radical producing treatment group. Comparatively, previous reported studies involving similar acid used here showed damages to the test plants, however, the present study has been able to speculate that similar damaging results could imply similar mechanisms of damage. In either case $\mathrm{OH}$ radical and other ROS are implicated (Kobayashi et al., 2002; Overmyer et al., 2003).

It can be said that the great contrast in the foliar assessments between the acids and photo Fenton solution treated cucumber plants and the control series that long term exposure of the duo (acid rain, photo Fenton reagents) had depleted the chlorophyll pigmentation, caused visible foliar injuries like chlorosis and even deadness of cells by necrotic lesions on their leaves. (Pic. 1a and Pic. 2a). Similar results were obtained for damages borne on Japanese red pine (Oguntimehin et al., 2013). All malady and poor foliar health are traceable to increased plant stress and the inability of the photosynthetic and chlorophyll apparatus from working properly. Such events may even lead to the total annihilation of the cucumber plants (Overmyer et al., 2003).

\section{Conclusion}

While many eco-physiological studies have proved the various roles of the ROS on plant growth and general health, it has not been able to show that similar mechanisms exist for the acid rain-induced phytotoxicity and the one brought about by the photo Fenton solutions. The present study has been able to link the duo and also to assess the extent of damage to the foliar and physiological changes resulting from the residences of the fumigants on the plant. Comparative examinations of the various mitigating solutions also revealed that the ameliorating impacts of mannitol cannot be undermined. Mannitol used at a minimal dosage as a scavenger of ROS as applied in this study can prevent possible negative and deleterious effects of pollutants in air or water whose damaging effects is proposed via ROS.

\section{Author's Contributions}

Fawzy Eissa: Contributed to the design and implementation of the experiments, processing the experimental data and to the analysis of the results. Wrote the manuscript with Ilemobayo Oguntimehin in consultation with Hiroshi Sakugawa.

Sayuri Bandai and Nour El-Hoda Zidan: Contributed to the design and implementation of the experiments, processing the experimental data and to the analysis of the results.

Ilemobayo Oguntimehin: Made considerable contributions in interpretation of data. Wrote the manuscript with Fawzy Eissa in consultation with Hiroshi Sakugawa.

Hiroshi Sakugawa: Contributed to the design and implementation of the experiments, processing the experimental data, analysis of the results and to the writing of the manuscript.

\section{Ethics}

This article is original and contains unpublished material. The corresponding author confirms that all of the other authors have read and approved the manuscript and no ethical issues involved.

\section{References}

Amthor, J.S., 1995. Higher Plants Respiration and its Relationships to Photosynthesis. In: Cited in Ecophysiology of Photosynthesis, Schulze, E.D. and M.M. Caldwell, Springer, Berlin Heidelberg, New York, pp: 71-95.

Asada, K., 2006. Production and scavenging of reactive oxygen species in chloroplasts and their functions. Plant Physiol., 141: 391-396.

DOI: $10.1104 /$ pp.106.082040

Bjorkman, O. and B. Demmig, 1987. Photon yield of $\mathrm{O}_{2}$ evolution and chlorophyll fluorescence characteristics at $77 \mathrm{~K}$ among vascular plants of diverse origins. Planta, 170: 489-504. DOI: $10.1007 / \mathrm{BF} 00402983$

Chiwa, M., T. Matsuda, N. Nakatani, Y. Sueki and T. Kobayashi et al., 2005. Physiological effects of hydroxyl radical $(\mathrm{OH})$ generating solution as simulated dew on the needle surfaces of Japanese Red Pine (Pinus densiflora) Sieb. et Zucc.). Phyton (Austria), 45: 237-244. 
Debnath, B., M. Irshad, S. Mitra, M. Li and H.M. Rizwan et al., 2018. Acid rain deposition modulates photosynthesis, enzymatic and non-enzymatic antioxidant activities in tomato. Int. J. Environ. Res., 12: 203-214. DOI: 10.1007/s41742-018-0084-0

Du, E., D. Dong, X. Zeng, Z. Sun and X. Jiang et al., 2017. Direct effect of acid rain on leaf chlorophyll content of terrestrial plants in China. Sci Total Environ., 605: 764-769.

DOI: $10.1016 /$ j.scitotenv.2017.06.044

Eamus, D. and D. Fowler, 1990. Photosynthetic and stomatal conductance responses to acid mist of red spruce seedlings. Plant Cell Environ., 13: 349-357. DOI: $10.1111 / \mathrm{j} .1365-3040.1990 . t b 02138 . x$

Jones, G.H., 1994. Plants and Microclimate: A Quantitative Approach to Environmental Plant Physiology. 2nd Edn., Cambridge University Press.

Karuppanapandian, T., A.R., Saranyadevi, K., Jeyalakshmi and K. Manoharan, 2008. Mechanism, control and regulation of leaf senescence in plants. $\mathrm{J}$. Plant Biol., 35: 141-155.

Karuppanapandian, T., J. Moon, C. Kim, K. Manoharan and W. Kim, 2011. Reactive oxygen species in plants: Their generation, signal transduction and scavenging mechanisms. AJCS, 5: 709-725.

Karuppanapandian, T., P.B. Sinha, G. Premkumar and K. Manoharan, 2006c. Chromium toxicity: Correlated with increased in degradation of photosynthetic pigments and total soluble protein and increased peroxidase activity in green gram (Vigna radiata L.) seedlings. J. Swamy Bot-Cl, 23:117-122.

Karuppanapandian, T., P.B. Sinha, K.A. Haniya and K. Manoharan, 2006a. Differential antioxidative responses of ascorbate-glutathione cycle enzymes and metabolites to chromium stress in green gram (Vigna radiata L. Wilczek) leaves. J. Plant Biol., 49: 440-447. DOI: 10.1007/BF03031124

Karuppanapandian, T., P.B. Sinha, K.A. Haniya, G. Premkumar and K. Manoharan, 2006b. Aluminiuminduced changes in antioxidative enzyme activities, hydrogen peroxide content and cell wall peroxidase activity in green gram (Vigna radiata L. cv. Wilczek) roots. J. Plant Biol., 33: 241-246.

Kobayashi, T., N. Nakatani, T. Hirakawa, M. Suzuki and T. Miyake et al., 2002. Variation in $\mathrm{CO}_{2}$ assimilation rate induced by simulated dew waters with different sources of hydroxyl radical $(\mathrm{OH})$ on the needle surfaces of Japanese red pine (Pinus densiflora Sieb. et Zucc.). Environ. Pollut., 118: 383-391. DOI: 10.1016/S0269-7491(01)00289-5

Langebartels, C., H. Wohlgemuth, S. Kschieschan, S. Grün and H. Sandermann, 2002. Oxidative burst and cell death in ozone-exposed plants. Plant Physiol. Biochem., 40: 567-575.

DOI: $10.1016 / \mathrm{S} 0981-9428(02) 01416-\mathrm{X}$
Lefohn, A.S., 1991. Surface-Level Ozone Exposures and Their Effects on Vegetation. 1st Edn., Lewis Publishers, Boca Raton, FL., ISBN-10: 0873711696, pp: 384.

Manahan, S.E., 2001. Fundamentals of Environmental Chemistry. 1st Edn., CRC Press, Boca Raton, pp: 206.

Markwell, J., J.C. Osterman and J.L. Mitchell, 1995. Calibration of the Minolta SPAD-502 leaf chlorophyll meter. Photosynth. Res., 46: 467-472. DOI: $10.1007 / \mathrm{BF} 00032301$

Mittler, R., 2002. Oxidative stress, antioxidants and stress tolerance. Trends Plant Sci., 7: 405-410. DOI: $10.1016 / \mathrm{S} 1360-1385(02) 02312-9$

Mittler, R., S. Vanderauwera, M. Gollery and F. Van Breusegem, 2004. Reactive oxygen gene network of plants. Trends Plant Sci., 9: 490-498. DOI: $10.1016 /$ j.tplants.2004.08.009

Nakatani, N., A. Kume, T. Kobayashi, T. Hirakawa and H. Sakugawa, 2004. Needle morphology related to chemical contents in the needles of Japanese Fir (Abies Firma) trees subjected to acidic deposition at Mt. Oyama, Eastern Japan. Water Air Soil Poll., 152: $97-110$. DOI: 10.1023/B:WATE.0000015343.24509.19

Navrot, N., N. Roubier, E. Gelbaye and J.P. Jacquot, 2007. Reactive oxygen species generation and antioxidant systems in plant mitochondria. Physiol. Plant., 129: 185-195.

DOI: $10.1111 /$ j.1399-3054.2006.00777.x

Oguntimehin, I. and H. Sakugawa, 2008. Fluoranthene fumigation and exogenous scavenging of Reactive Oxygen Intermediates (ROI) in evergreen Japanese red pine seedlings (Pinus densiflora Sieb. et. Zucc.). Chemosphere, 72: 747-754.

DOI: 10.1016/j.chemosphere.2008.03.022

Oguntimehin, I., F. Eissa and H. Sakugawa, 2010a. Negative effects of Fluoranthene on the ecophysiology of tomato plants (Lycopersicon esculentum Mill). Chemosphere, 78. 877-884.

DOI: $10.1016 /$ j.chemosphere.2009.11.030

Oguntimehin, I., F. Eissa and H. Sakugawa, 2010 b. Simultaneous ozone fumigation and fluoranthene sprayed as mists negatively affected cherry tomato (Lycopersicon esculentum Mill). Ecotoxicol. Environ. Saf., 73: 1028-1033.

DOI: $10.1016 /$ j.ecoenv.2010.04.003

Oguntimehin, I., S. Bandai and H. Sakugawa, 2013. Mannitol can mitigate negative effects of simulated acid mist and fluoranthene in juvenile Japanese red pine ( $P$. densiflora Sieb. et Zucc). Environ. Pollut., 174: 78-84. DOI: 10.1016/j.envpol.2012.10.023

Overmyer, K., M. Brosche and J. Kangasjarvi, 2003. Reactive oxygen species and hormonal control of cell death. Trends Plant Sci., 8: 325-342. DOI: 10.1016/S1360-1385(03)00135-3 
Sakugawa, H., N. Hasan, I. Oguntimehin and E. Belal, 2012. Protective and curative effects of foliar-spray Fenton solutions against cucumber (Cucumis sativus, L) Powdery Mildew. J. Environ. Sci. Heal A., 47: 1909-1918.

DOI: $10.1080 / 03601234.2012 .676448$

Shan, Y., 1998. Effects of simulated acid rain on Pinus densiflora: Inhibition of net photosynthesis by pheophytization of chlorophyll. Water Air Soil Pollut., 103: 121-127.

DOI: $10.1023 / \mathrm{A}: 1004921511269$

Shu, X., K. Zhang, Q. Zhang and W. Wang, 2019. Ecophysiological responses of Jatropha curcas L. seedlings to simulated acid rain under different soil types. Ecotox. Environ. Safe., 185: 109705-109705. DOI: 10.1016/j.ecoenv.2019.109705

Trebst, A., 1995. Dynamics in Photosystem II Structure and Function. In: Ecophysiology of Photosynthesis, Schulze, E.D. and M.M. Caldwell (Eds.), SpringerVerlag Berlin Heidelberg, pp: 3-15.
USEPA, 2010. Acid rain in New England: in United State Environmental Protection Agency (USEPA) report.

Vollenweider, P., M. Ottiger and M.S. GunthardtGeorge, 2003. Validation of leaf ozone symptoms in natural vegetation using microscopial methods. Environ. Pollut., 124: 101-118. DOI: $10.1016 / \mathrm{S} 0269-7491(02) 00412-8$

Yoon, J., M. Abe-Suzuki, P. Eko, H. Tamai and S. Hanamitsu et al., 2006. Negative effects of hydroxyl radical-generating mists (simulated dew water) on the photosynthesis and growth of Japanese apricot seedlings (Prunus mume). Ecol. Res., 21: 117-125. DOI: $10.1007 / \mathrm{s} 11284-005-0112-3$

Zhang, C., X. Yi, X. Gao, M. Wang and C. Shao et al., 2020. Physiological and biochemical responses of tea seedlings (Camellia sinensis) to simulated acid rain conditions. Ecotox. Environ. Safe., 192: 110315-110315.

DOI: 10.1016/j.ecoenv.2020.110315 